\title{
MEPERIDINE AND MORPHINE AS INTRAVENOUS SURGICAL PREMEDICANTS
}

\author{
James T. Conner, J. Weldon Bellville, and Ronald L. Katz
}

SuRGICAL PATIENTS are more often than not premedicated with a narcotic. A review of the literature reveals few well-designed studies comparing the effects of narcotics used as surgical premedicants. We chose two of the most commonly used narcotics, meperidine and morphine, for study. Relief of anxiety, sedation, patient acceptance, lack of recall, and side effects were evaluated.

\section{Methods}

One hundred and sixty patients between the ages of 18 and 70 years participated in the study. Patients with a history of allergy to the study drugs, patients in pain pre-operatively and patients undergoing cardiac surgery, biliary tract surgery, and neurosurgery were excluded from the study. No limitations were otherwise made on the type of surgery or anaesthesia. No patient had received any other narcotic or sedative prior to operation.

Meperidine $50 \mathrm{mg}$ and $100 \mathrm{mg}$ and morphine $5 \mathrm{mg}$ and $10 \mathrm{mg}$ were the drugs studied. Each group consisted of 40 patients. The drugs were given intravenously by a physician over a one-minute period in a pre-operative holding room where the patient was brought approximately one hour prior to surgery. A double blind technique was used according to a randomized Latin square sequence. A trained nurse observer stayed with each patient throughout the pre-operative period.

Before receiving the drug, each patient was asked to rate his own level of anxiety as negligible, mild, moderate or severe. Fifteen minutes after injection, the nurse observer without informing the patient rated his sedation as unchanged $(0)$, improved $(1+, 2+, 3+$ or $4+)$, or worsened $(1-, 2-, 3-, 4-)$, as compared to his unpremedicated state. The patient was then asked to evaluate his level of anxiety in a similar manner again in comparison to his unpremedicated state. This procedure was repeated 30 minutes after administration of the drug.

Also, at 15 minutes a "memory card" (large picture of a dollar bill) was shown to the patient.

Twenty-four hours after operation, the post-operative evaluations were conducted by the nurse observer. The patient was asked to evaluate the medication as poor $(0)$, fair $(1+)$, good $(2+)$, or excellent $(3+)$ using the patient's own subjective criteria to rate the drugs.

Recall was tested at this time by asking the patient if he recollected the "memory

James T. Conner, M.D., Assistant Professor, Anesthesiology. J. Weldon Bellville, M.D., Professor, Anesthesiology. Ronald L. Katz, M.D., Professor and Chairman, Department of Anesthesiology.

Department of Anesthesiology, UCLA School of Medicine, Los Angeles, California 90024. 
card". If not, he was shown a composite picture which included the "memory card" among eight pictures. The patient was also asked if he recalled the pre-operative room and the operating room.

Anaesthesia, recovery room, and post-operative records were reviewed for surgical or anaesthetic complications which might be related to the study drugs.

Statistical analysis of data was made using ridit transformation. ${ }^{1}$ We use this nonparametric statistic because the ridit tends to normalize skewed data. The total number of patients within the study is used as a reference set. All comparisons are thus made within the reference set giving arbitrary classifications ( 0 to $4+$ ) a valuable interpretation in terms of probabilities. A higher ridit score indicates a greater drug effect and a lower score indicates a lesser effect. Two standard deviations for ridit transformation is calculated as $2 s d=1 \sqrt{3 n}$. Thus for 40 patients per group $2 s d=0.091$ with differences greater than this being statistically significant $(\mathrm{P}<0.05)$. The mean ridit score for any variable is 0.5 in the total population.

Examination of patient variables such as age, height, weight, male/female ratio, race, type of anaesthesia and operation did not reveal any marked differences in the study groups. This indicates that the randomization process was effective in balancing variables which might otherwise bias the study.

\section{RESULTS}

Anxiety. The patient's scoring of his change in anxiety as compared to his unpremedicated state was tabulated for the 15-minute and 30-minute evaluations. The mean raw score for relief of anxiety is shown in Table $I$ and plotted in Figure I using the ridit transformation. Meperidine $50 \mathrm{mg}$ and $100 \mathrm{mg}$ scored higher than morphine $5 \mathrm{mg}$ and $10 \mathrm{mg}$ respectively for both time observations. This difference is not statistically significant. The dose-effect curve is not significant for morphine or meperidine. There is no statistically significant difference for anxiety scores between 15 and 30 minutes for any of the study drugs.

TABLE I

\begin{tabular}{|c|c|c|c|c|}
\hline & $\begin{array}{l}\text { Morphine } \\
\overline{5} \text { mg }\end{array}$ & $\begin{array}{l}\text { Morphine } \\
10 \mathrm{mg}\end{array}$ & $\begin{array}{l}\text { Meperidine } \\
50 \mathrm{mg}\end{array}$ & $\begin{array}{c}\text { Meperidine } \\
100 \mathrm{mg}\end{array}$ \\
\hline \multicolumn{5}{|l|}{ Patient anxiety $(0- \pm 4)$} \\
\hline 15 minutes & 1.41 & 1.51 & 1.66 & 1.70 \\
\hline 30 minutes & 1.59 & 1.55 & 1.55 & 1.79 \\
\hline \multicolumn{5}{|l|}{ Sedation $(0- \pm 4)$} \\
\hline 15 minutes & 1.24 & 1.41 & 1.63 & 2.00 \\
\hline 30 minutes & 1.43 & 1.13 & 1.19 & 1.87 \\
\hline \multicolumn{5}{|l|}{ Acceptance score $(0-3)$} \\
\hline At 24 hours & 1.62 & 1.72 & 1.83 & 1.85 \\
\hline \multicolumn{5}{|l|}{$\begin{array}{l}\text { Patient acceptance: number } \\
\text { of patients/percentage }\end{array}$} \\
\hline Poor & $4-10$ & $5-13$ & $3-8$ & $4-10$ \\
\hline Fair & $13-33$ & $9-23$ & $12-30$ & $7-18$ \\
\hline Good & $16-41$ & $17-44$ & $14-35$ & $20-50$ \\
\hline Excellent & $6-15$ & $8-20$ & $11-28$ & $9-22$ \\
\hline \multicolumn{5}{|l|}{ Failure to recall memory } \\
\hline card & 0 & 0 & 0 & 0 \\
\hline \multicolumn{5}{|l|}{ Failure to recall operating } \\
\hline room & 0 & 0 & 0 & 0 \\
\hline Nausea (percentage) & 2.5 & 10 & 17.5 & 12.5 \\
\hline Vomiting (percentage) & 2.5 & 0 & 2.5 & 0 \\
\hline
\end{tabular}


CHANGE IN PATIENT ANXIETY
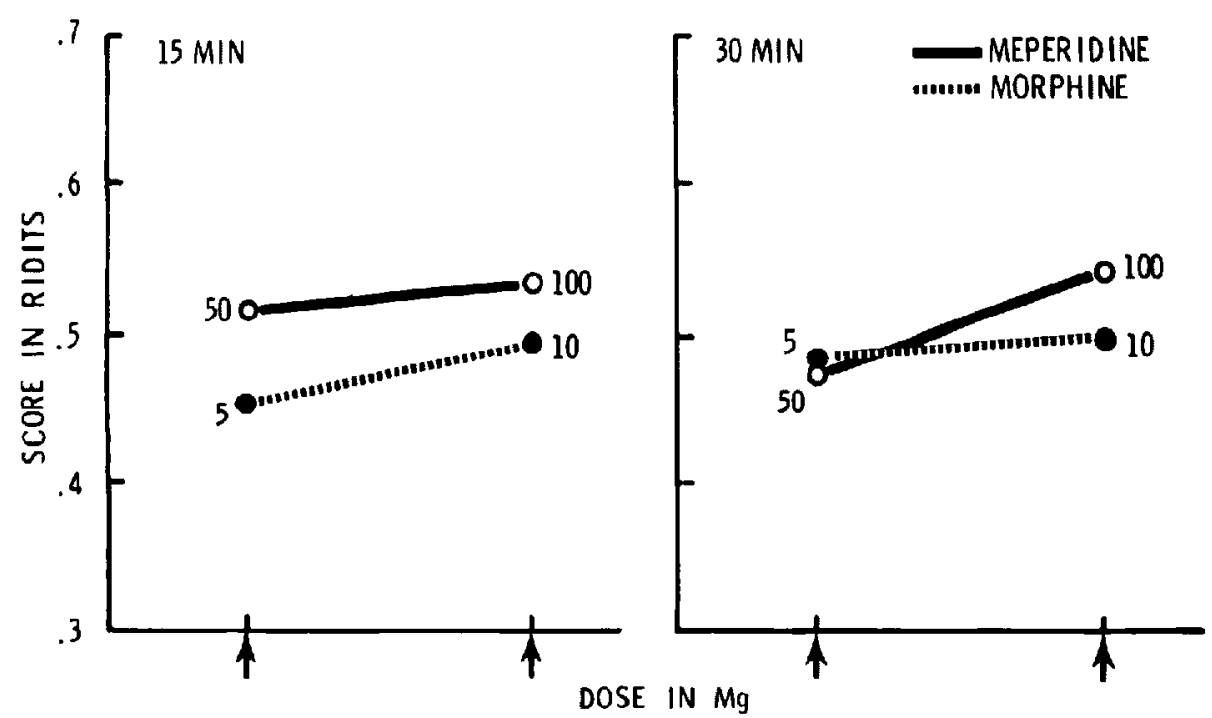

FIGUne 1. The mean change in anxiety in ridits as scored by the patient at 15 minutes and 30 minutes is plotted against the dose of morphine and meperidine. The higher the ridit score the greater the relief of anxiety. A difference greater than 0.091 ridits is statistically significant $(\mathrm{P}<0.05)$.

Sedation. The nurse observer's scoring of the patient's change in sedation as compared to his unpremedicated state was tabulated for the 15-minute and 30-minute evaluations. The mean raw score for sedation is listed in Table I and plotted in Figure 2 using the ridit transformation. Meperidine $50 \mathrm{mg}$ and $100 \mathrm{mg}$ scored statistically significantly higher $(P<0.05)$ than morphine $5 \mathrm{mg}$ and $10 \mathrm{mg}$ respectively for both time observations with the exception of the 30-minute observation of meperidine $50 \mathrm{mg}$ and morphine $5 \mathrm{mg}$. Thirty-minute evaluation scores of each drug did not significantly differ from 15-minute evaluation scores.

Patient Acceptance. The patient acceptance data obtained by the nurse observer 24 hours after operation is listed in Table I and plotted in Figure 3. Neither meperidine nor morphine showed a significant dose-effect slope. Meperidine did score higher than morphine but this was not statistically significant at the 5 per cent level.

Effect on Recall. Recall of the memory card and of entering the operating room is listed in Table I. Neither meperidine nor morphine had any effect on recall.

Side Effects. The incidence of pre-operative nausea and vomiting is listed in Table I. These were the only side effects elicited. There was more nausea with meperidine (12 patients) than with morphine (five patients). Vomiting occurred in only two patients, one each with morphine and meperidine. There were no marked changes in vital signs prior to operation. Review of anaesthesia, recovery room, and post-operative records did not reveal any serious complications which were related to the study drugs. 

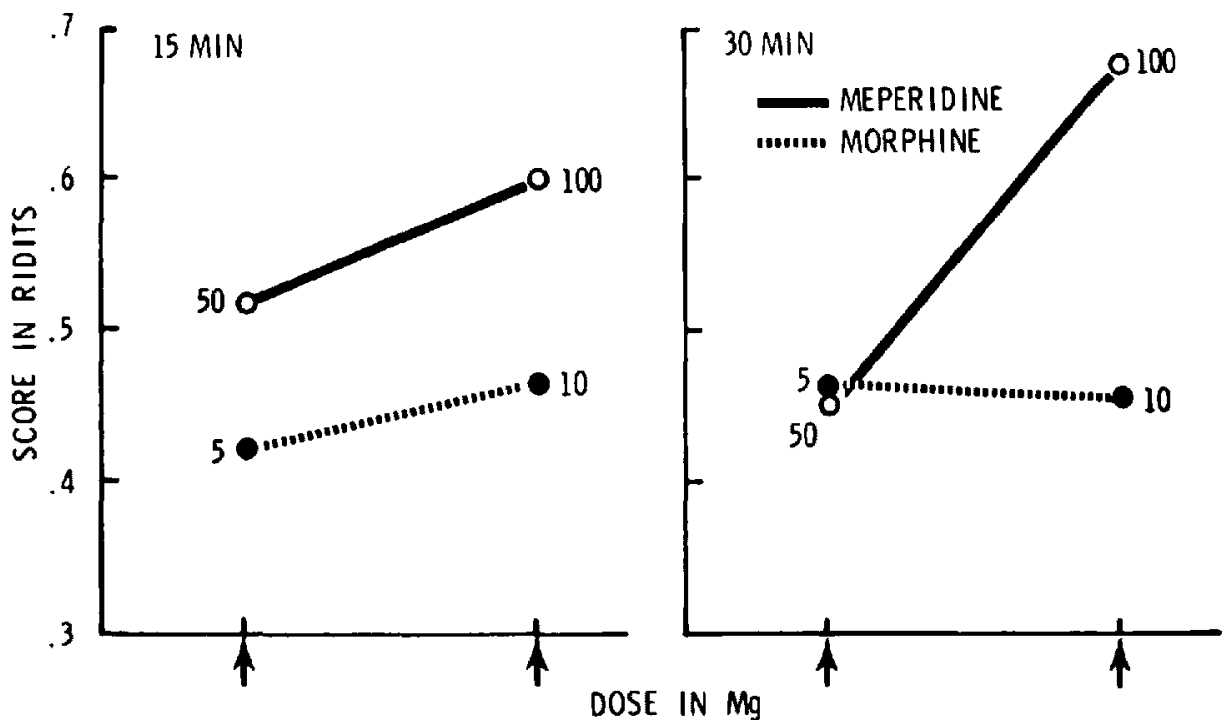

Figure 2. The mean change in sedation in ridits as scored by the nurse observer at 15 minutes and 30 minutes is plotted against the dose of morphine and meperidine. The higher the ridit score the greater the sedation. A difference greater than 0.091 ridits is statistically significant $(\mathrm{P}<0.05)$.

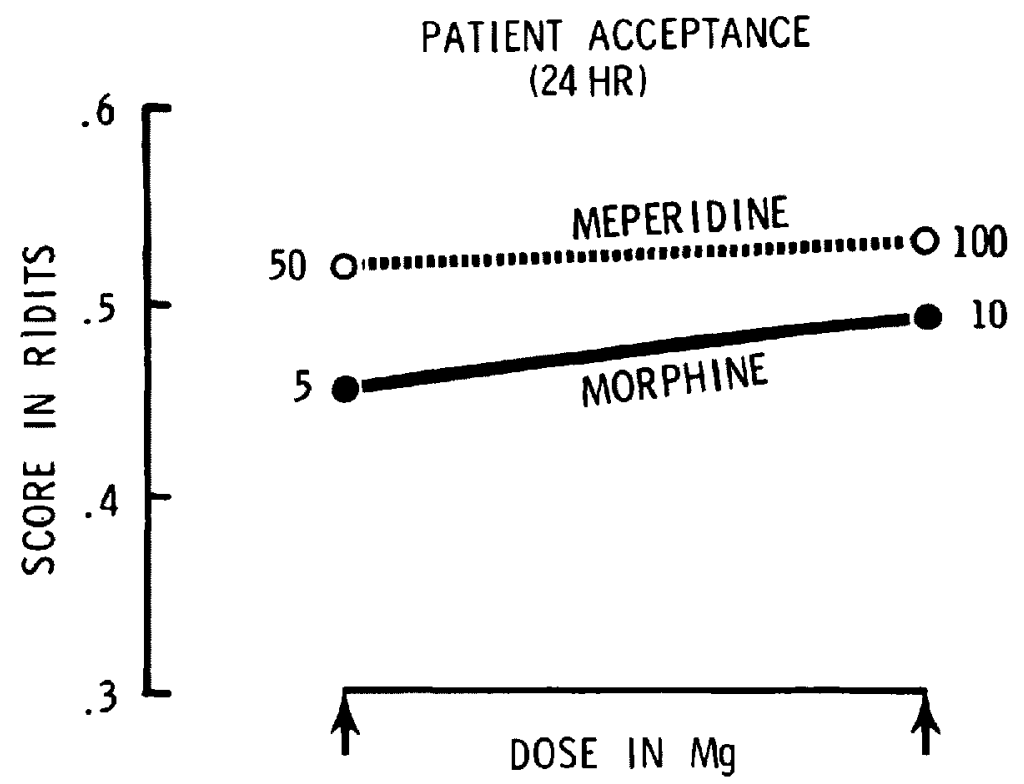

Figure 3. The mean patient acceptance in ridits as scorcd by the patient 24 hours after operation. The higher the ridit score, the better the patient acceptance. A difference greater than 0.091 is statistically significant $(P<0.05)$. 


\section{Discussion}

Narcotics are often used routinely as surgical premedicants. This practice has persisted in spite of the criticism of such use in classic papers by Cohen and Beecher" and Eckenhoff and Helrich." These authors found that pentobarbitone produced sedation equivalent to morphine and meperidine, but with fewer side effects.

This study compares intravenous meperidine $50 \mathrm{mg}$ and $100 \mathrm{mg}$ and morphine $5 \mathrm{mg}$ and $10 \mathrm{mg}$ alone. There nppear to be no significant differences between meperidine and morphine given intravenously in relief of anxiety, sedation, patient acceptance and lack of recall. What differences there were tended to favor meperidine, but this might be explained by the fact that the relative potency of morphine to meperidine is slightly less than 10:1.

Neither morphine nor meperidine scores particularly high in any of the categories studied. For the most part patients were far from euphoric after receiving the drugs and the majority of the patients did not find much relief of anxiety. In marked contrast to our experience with the benzodiazepines, ${ }^{4}$ there was no lack of recall with any of the study drugs. Likewise sedation scores and patient acceptance were not good. Patients generally complained of unpleasant side effects, particularly the "rush" ascribed to intravenous narcotics. These initial sensations of flushing, tightness in chest and neck, heaviness, dizziness, etc. usually subsided in five to ten minutes, however.

Several studies of intramuscular meperidine and morphine as surgical premedicants indicate an incidence of nausea, vomiting, and dizziness similar to that seen in this study. ${ }^{5,6}$ These symptoms may conceivably be less bothersome to the patient when the drugs are given by the intramuscular route because of a slower onset and lower peak blood levels. A study comparing intravenous and intramuscular narcotics would be helpful in clarifying these points.

\section{SUMMARY}

Morphine $5 \mathrm{mg}$ and $10 \mathrm{mg}$ and meperidine $50 \mathrm{mg}$ and $100 \mathrm{mg}$ were studied as intravenous surgical premedicants in 160 patients. Relief of anxiety, sedation, lack of recall and side effects were the variables evaluated. Neither morphine nor meperidine proved to be particularly good surgical premedicants. There appeared to be no significant differences between the two drugs, but what differences there were tended to favor meperidine.

\section{RÉSUMÉ}

Nous avons évalué la morphine intraveineuse à la dose de 5 ou $10 \mathrm{mg}$, ainsi que la mépéridine intraveineuse à raison de $50 \mathrm{ou} 100 \mathrm{mg}$ comme agents de prémédication chez 160 opérés.

Les critères évalués étaient la soulagement de l'anxiété, la sédation produite, l'absence de souvenir et les effets secondaires. Ni l'un ni l'autre des deux narcotiques ne s'est avéré particulièrement bon comme agent de prémédication. Il 
ne semblait pas y avoir de différence significative entre les deux, mais si une tendance se dessinait, elle était en faveur de la mépéridine.

\section{REFERENCES}

1. Bross, I.D.K. How to use ridit analysis. Biometrics $14: 18-26$ ( 1958 ).

2. CoheN, E.N. \& BeEcher, H.K, Narcotics in preanesthetic medication - a controlled study. JAMA 147: 1664-1669 (1951).

3. EскеNнoff, E. \& Hel.rich, M. Study of narcotics and sedatives for use in preanesthetic medication. JAMA 167: 415-421 (1958).

4. Conner, J.T., Katz, R.L., Graham, C., et al. Diazepam and lorazepam as intravenous surgical premedicants. Submitted for publication.

5. Dundee, J.W., Clarke, R.S.J., \& LOAN, W.B. A comparison of the sedative and toxic effects of morphine and pethidine. Lancet 2: 1262-1263 (1965).

6. Clahke, R.S.J., Dundee, J.W., \& Love, W.J. Studies of drugs given before anaesthesia VIII: morphine $10 \mathrm{mg}$ alone and with atropine or hyoscine. Brit. J. Anaesth. 37: 772-777 (1965). 